\title{
A systematic review and meta-analysis of the correlation between cough variant asthma and mycoplasma pneumonia in children
}

\author{
Luyan Jiao, Guoqing Zhang, Yi Yuan, Ling Cao
}

Department of Pulmonology, Children's Hospital of Capital Institute of Pediatrics, Beijing, China

Submitted: 14 September 2020; Accepted: 7 November 2020

Online publication: 9 May 2021

Arch Med Sci

DOI: https://doi.org/10.5114/aoms/130286

Copyright $\odot 2022$ Termedia \& Banach

\section{Abstract}

Introduction: The aim of the present study was to explore the correlation between cough variant asthma (CVA) and repeated episodes of mycoplasma pneumonia in children.

Material and methods: Multiple databases were searched for relevant studies, and the articles that eventually satisfied the inclusion criteria were included. All the meta-analyses were conducted with Review Manager 5.2. To estimate the quality of each article, the risk of bias table was used. In total, 1223 patients with CVA and 1437 patients with simple cough (SC) were included.

Results: Finally, 9 studies including 2660 patients were included, who eventually satisfied the eligibility criteria. The results of the heterogeneity test suggested that the serum level of IgE $(M D=80.69,95 \% \mathrm{Cl}: 77.75-83.62$, $p<0.001 ; p$ for heterogeneity $\left.<0.001, l^{2}=95 \%\right)$, eosinophil count $(\mathrm{MD}=$ 2.93, 95\% Cl: $2.72-3.13, p<0.001 ; p$ for heterogeneity $<0.001, l^{2}=71 \%$ ) and the number of children with positive IgM $(\mathrm{OR}=4.44,95 \% \mathrm{Cl}: 3.73-5.29$, $p<0.001 ; p$ for heterogeneity $=0.63, l^{2}=0 \%$ ) were significantly different. The value of IgE in CVA was higher than that in SC, eosinophil count in CVA was higher than that in SC and the number of IgM positive children in the CVA group was higher than that in the SC group.

Conclusions: This study demonstrated a correlation between cough variant asthma and mycoplasma pneumonia.

Key words: cough variant asthma, mycoplasma pneumonia, children.

\section{Introduction}

Asthma is the most common chronic childhood disease in the world. According to the guidelines of the World Health Organization on Integrated Management of Childhood IIlness $(\mathrm{IMCl})$, the diagnosis of asthma is based on the presence of wheezing [1-3]. It is closely associated with childhood asthma and bronchiolitis. Cough variant asthma (CVA) mainly has features such as repeated episodes of coughing and prolonged treatment [4-6]. Long term irritant dry cough, less sputum and other severe symptoms may occur when cold irritation or pollen allergens gain access. Cough variant asthma is a special type of asthma and chronic cough (cough lasts for more than 8 weeks and chest X-ray shows no evidence of lung disease) is a main manifestation. In children with CVA, IgM

\author{
Corresponding author: \\ Ling Cao \\ Department of Pulmonology \\ Children's Hospital \\ of Capital Institute \\ of Pediatrics \\ No. 2 Yabao Road \\ Chaoyang District, Beijing, \\ 100020, China \\ Phone: +86-010-85695629 \\ E-mail: caoling9919@163. \\ com
}


antibody level, serum total lgE level and peripheral eosinophil count should be determined to rule out Mycoplasma pneumoniae. In a study based on 10000 samples, the highest age of developing CVA among children is 3-6 years, the ratio of incidence between boys and girls is 1.42:1 and CVA accounts for $14-33 \%$ of the causes of chronic cough [1].

In low-income countries, pneumonia is considered to be the main cause of respiratory disease and death among children under 5 years of age $[7,8]$. Mycoplasma pneumoniae is a pathogenic microorganism, which is mainly adsorbed on the surface of the airway mucous membrane [9-11]. It destroys the secretion of airway epithelial cells and glands, inhibiting cilium movement and so on. This can cause chronic inflammatory changes in the respiratory system. After long-term mycoplasma pneumonia, the airway smooth muscle becomes contracted, leading to dysfunction of non-cholinergic nerves, airway responsiveness, exacerbating inflammation and migrating disease [11].

The relationship between Mycoplasma pneumoniae infection and asthma has become a hot topic. Because of genetic differences among individuals, chronic and nonspecific airway inflammation leads to edema of the airway mucous membrane, increased mucus secretion and spasm of bronchial smooth muscles. Further studies on the etiology and determinants of asthma suggest that Mycoplasma pneumoniae is one of the pathogens associated with acute or chronic asthma [10].

Since the association between CVA and Mycoplasma pneumoniae still needs to be analyzed, an exploration of the relationship was conducted. This study aimed to analyze the relationship between CVA and Mycoplasma pneumoniae infection in children.

\section{Material and methods}

\section{Search strategy}

The main aim of this study was to evaluate the relationship between CVA and Mycoplasma pneumoniae. To identify all of the relevant publications, multiple electronic databases including PubMed, Springer, EMBASE, OVID and China Journal Fulltext Database were searched, without language restrictions. To increase search accuracy, the following MeSH (Medical Subject Headings) terms were assembled with the Boolean operator "AND": (1) Cough variant asthma OR CVA; (2) Mycoplasma pneumoniae OR MP; (3) Child OR Children. Related articles with all publication statuses (published, unpublished, in press and in progress) published from January 2000 to January 2020 were systematically searched and reviewed. Two authors in our team searched the literature independently and examined the reference lists to obtain additional relevant studies that were not identified.

\section{Study selection}

Two authors selected the citations independently in this study with the following in clusion criteria: (1) pediatric patients with CVA; (2) sample size more than 10; (3) randomized controlled trial or controlled clinical trial; (4) availability of full text; (5) since clinical laboratories can provide diagnostic testing for $M y$ coplasma pneumoniae infections using culture, serology, or nucleic acid amplification methods, blood test results should be reported. The exclusion criteria were: (1) patients without CVA or adult patients; (2) sample size was less than 10; (3) case report or meta-analysis; (4) results about patients were ineligible. They screened the titles and abstracts of the articles identified, and subsequently, the full text of the studies that potentially met the criteria was obtained. These two investigators determined the included articles together, and disagreements were resolved by consultation with a third investigator if necessary.

\section{Data extraction}

After reading the full text of the articles, we extracted the characteristics from each study using a standard data extraction method: the first author's name, year of publication, nation, age range of patients, sex (male/female), sample size (cough variant asthma (CVA)/simple cough (SC)), follow-up duration, and other parameters. SC patients only had cough without other symptoms.

\section{Statistical analysis}

The meta-analyses were conducted with the software Review Manager 5.2 (The Cochrane Collaboration, 2011) to estimate the association between cough variant asthma and Mycoplasma pneumoniae in child patients. For continuous outcomes, standard mean difference (SMD) with 95\% confidence interval $(\mathrm{Cl})$ was calculated. For discontinuous outcomes, odds ratio (OR) with $95 \% \mathrm{Cl}$ was conducted. A $p$ value $<0.05$ was considered to be statistically significant. Heterogeneities in this study were assessed using the $I^{2}$ index. We chose the random-effects model when the heterogeneity $l^{2}$ statistic was $>50 \%$; otherwise, the fixed-effects model was applied.

In addition, the quality of the studies was assessed with sensitivity analysis and bias analysis. The risk of bias table of the included studies was independently assessed according to the Cochrane Handbook for Systematic Reviews of Interventions by two members of our team. In addition, if there was poor agreement and no consensus could be achieved, a third investigator was the adjudicator. 


\section{Results}

\section{Search results}

As shown in the flow diagram (Figure 1), 1031 relevant studies were initially identified, and 1022 articles were excluded due to duplication, irrelevant studies, incomplete data, incomplete comparison, other diseases and lack of the full text. Finally, 9 articles[12-20] satisfied the inclusion criteria. Among these 9 articles, 7 articles were published in English and 2 articles in Chinese. The study selection process is shown in Figure 1.

\section{Characteristics of included studies}

The detailed characteristics of the included studies, including first author's name, year of publication, nation, recruitment time, age range of patients, sex (male/female), sample size (CVA/SC), follow-up period, and other parameters, are presented in Table I. All these studies were published in the period from 2000 to 2018 . The sample size ranged from 53 to 600 . In total, 1223 patients with CVA were included in these studies, and 1437 were patients with SC.

\section{Quality assessment}

The bias table in the Review Manager 5.2 Tutorial was used to evaluate the risk of each study by applying the criteria for evaluating design-related bias. The evaluation in this study is shown

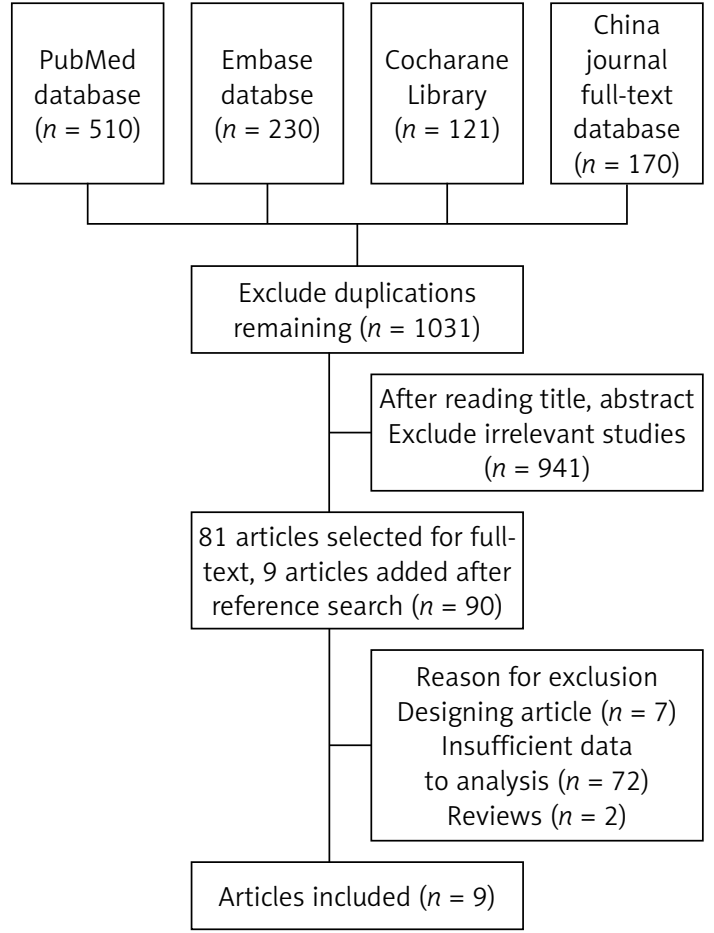

Figure 1. Flow diagram of study selection

Table I. Characteristics of studies included in the meta-analysis

\begin{tabular}{|c|c|c|c|c|c|c|c|c|}
\hline Study & Year & Language & Country & $\begin{array}{c}\text { Number } \\
\text { of patients } \\
\text { (female/male) }\end{array}$ & $\begin{array}{l}\text { Age range } \\
\text { (mean) }\end{array}$ & Groups & $n$ & Years of onset \\
\hline \multirow[t]{2}{*}{ Li [12] } & \multirow[t]{2}{*}{2017} & \multirow[t]{2}{*}{ Chinese } & \multirow[t]{2}{*}{ China } & \multirow[t]{2}{*}{$86 / 110$} & \multirow[t]{2}{*}{$6.1 \pm 1.3$} & CVA & 106 & \multirow{2}{*}{$\begin{array}{l}\text { October } 2009 \\
\text { to March } 2012\end{array}$} \\
\hline & & & & & & SC & 90 & \\
\hline \multirow{2}{*}{$\begin{array}{l}\text { Marchand } \\
{[13]}\end{array}$} & \multirow[t]{2}{*}{2003} & \multirow[t]{2}{*}{ English } & \multirow[t]{2}{*}{ France } & \multirow[t]{2}{*}{$34 / 19$} & \multirow[t]{2}{*}{$6.8 \pm 2.3$} & CVA & 26 & \multirow{2}{*}{$\begin{array}{l}\text { April } 1995 \\
\text { to June } 2002\end{array}$} \\
\hline & & & & & & SC & 27 & \\
\hline \multirow[t]{2}{*}{ Juhn [14] } & \multirow[t]{2}{*}{2008} & \multirow[t]{2}{*}{ English } & \multirow[t]{2}{*}{ Korea } & \multirow[t]{2}{*}{$258 / 264$} & \multirow[t]{2}{*}{$5.7 \pm 2.4$} & CVA & 174 & \multirow{2}{*}{$\begin{array}{l}\text { June } 2001 \\
\text { to March } 2006\end{array}$} \\
\hline & & & & & & SC & 348 & \\
\hline \multirow[t]{2}{*}{ Jung [15] } & \multirow[t]{2}{*}{2010} & \multirow[t]{2}{*}{ English } & \multirow[t]{2}{*}{ Korea } & \multirow[t]{2}{*}{$258 / 260$} & \multirow[t]{2}{*}{$6.5 \pm 3.1$} & CVA & 170 & \multirow{2}{*}{$\begin{array}{l}\text { May } 2003 \\
\text { to June } 2008\end{array}$} \\
\hline & & & & & & SC & 348 & \\
\hline \multirow[t]{2}{*}{ Chan [16] } & \multirow[t]{2}{*}{2015} & \multirow[t]{2}{*}{ English } & \multirow[t]{2}{*}{ America } & \multirow[t]{2}{*}{$312 / 288$} & \multirow[t]{2}{*}{$5.9 \pm 1.9$} & CVA & 242 & \multirow{2}{*}{$\begin{array}{c}\text { June } 2003 \\
\text { to March } 2011\end{array}$} \\
\hline & & & & & & SC & 163 & \\
\hline Nantanda & 2013 & English & Denmark & $200 / 166$ & $5.5 \pm 2.7$ & CVA & 203 & August 2011 \\
\hline & & & & & & SC & 163 & to June 2012 \\
\hline Romero- & 2018 & English & Germany & $55 / 65$ & $5.2 \pm 2.9$ & CVA & 42 & January 2013 \\
\hline Espinoza [18] & & & & & & SC & 78 & to January 2015 \\
\hline Nantanda & 2014 & English & Uganda & $180 / 186$ & $5.6 \pm 2.7$ & CVA & 200 & August 2011 \\
\hline & & & & & & SC & 160 & 012 \\
\hline Gui [20] & 2017 & Chinese & China & $54 / 66$ & $6.9 \pm 2.3$ & CVA & 60 & January 2014 \\
\hline & & & & & & SC & 60 & to March 2 \\
\hline
\end{tabular}

CVA - cough variant asthma, SC - simple cough.

in Figures 2 and 3. In the 9 articles, 1 trial showed a problem in patient selection and 1 showed a problem in attrition bias. Overall, all the trials were free of risk. 
Random sequence generation (selection bias)

Allocation concealment (selection bias) Blinding of participants and personnel (performance bias) Blinding of outcome assessment (detection bias) Incomplete outcome data (attrition bias) Selective reporting (reporting bias) Other bias

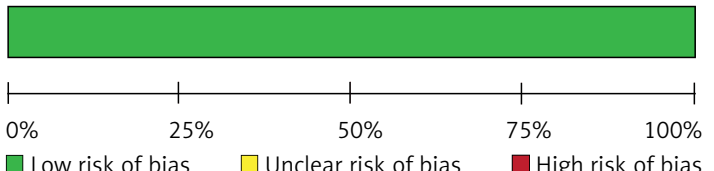

Figure 2. Assessment of quality of included studies: low risk of bias (green hexagons), unclear risk of bias (blank hexagons), and high risk of bias (red hexagons)

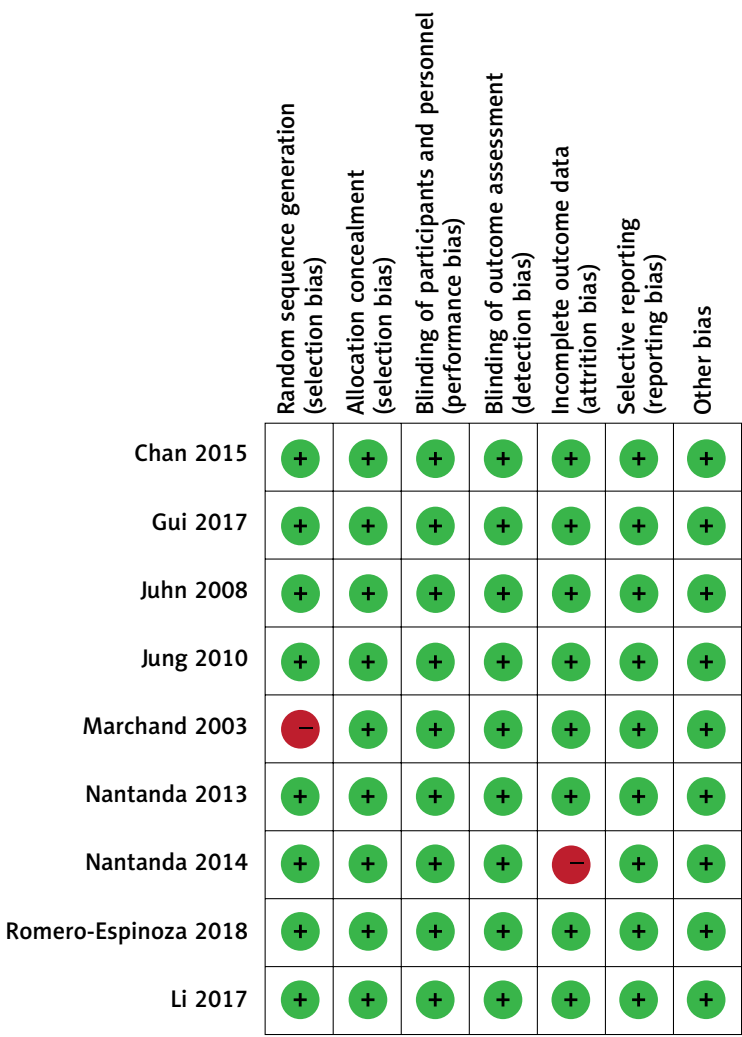

Figure 3. Quality assessment of included studies

\section{Results of meta-analysis}

Meta-analysis of serum IgE level in CVA and SC patients

Nine studies compared serum IgE level in CVA and SC patients. The forest plot for serum IgE level in different groups is shown in Figure 4. Total IgE was detected by immunoturbidimetry. All these studies reported that serum IgE levels were statistically significantly different between CVA and SC patients. The value of IgE in CVA patients $(M D=167.85)$ was higher than that in SC patients (MD $=90.29)$. The overall result is shown in
Figure $4(\mathrm{MD}=80.69,95 \% \mathrm{Cl}: 77.75-83.62$ $p<0.001 ; p$ for heterogeneity $\left.<0.001, l^{2}=95 \%\right)$.

\section{Meta-analysis of eosinophil count in CVA and SC patients}

Nine studies comparing eosinophil count showed a statistically significant difference (Figure 5). Eosinophil count was detected by a blood cell counter. The meta-analysis indicated that eosinophil count in patients with CVA (MD $=6.56)$ was higher than in patients with $\mathrm{SC}(\mathrm{MD}=3.53)$ $(\mathrm{MD}=2.93,95 \% \mathrm{Cl}: 2.72-3.13, p<0.00001 ; p$ for heterogeneity $<0.001, I^{2}=71 \%$ ).

\section{Meta-analysis of the number of IgM positive CVA and SC patients}

Nine studies compared the number of IgM (antiIgM for mycoplasma pneumonia) positive CVA and SC patients. The determination of serum IgM was as follows: $2 \mathrm{ml}$ of blood was extracted from children and centrifuged at 2000 rpm. Serum IgM was extracted by passive agglutination, and then frozen in the refrigerator at $15^{\circ} \mathrm{C}$ and $\lg M>1: 80$ was considered positive [7].

The meta-analysis showed a statistically significant difference in the number of positive IgM cases between CVA and SC patients (OR $=4.44$, 95\% Cl: 3.73, 5.29, $p<0.001 ; p$ for heterogeneity $=0.63, I^{2}=0 \%$ ) (Figure 6 ). The number of IgM positive patients in the CVA group (MD $=73.67)$ was higher than that in the SC group (MD = 33.12).

\section{Sensitivity analysis}

According to the results of the meta-analyses, the heterogeneity of serum IgE level was very high $\left(I^{2} \geq 95 \%\right)$. As shown in Figure 7 , the high heterogeneity of serum IgE level was probably due to differences in the studies. When the study in 2008 by Juhn [14] was excluded, $I^{2}$ changed from $95 \%$ to 


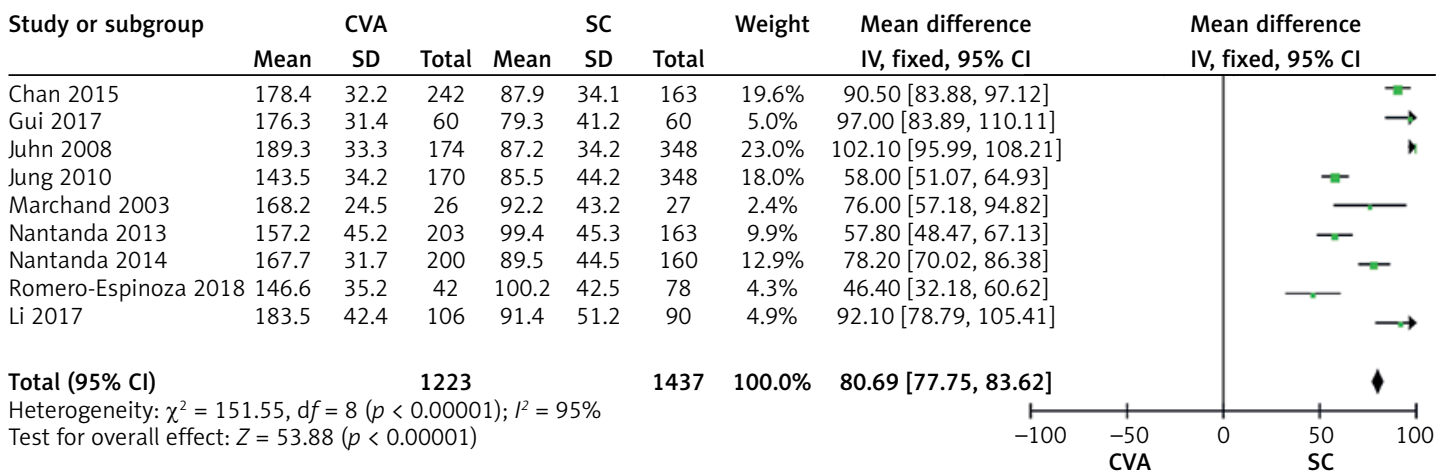

Figure 4. Forest plot for serum IgE level between cough variant asthma (CVA) and simple cough (SC)

\begin{tabular}{|c|c|c|c|c|c|c|c|c|c|c|c|}
\hline \multirow[t]{2}{*}{ Study or subgroup } & \multicolumn{3}{|c|}{ CVA } & \multicolumn{3}{|c|}{ SC } & \multirow[t]{2}{*}{ Weight } & \multirow{2}{*}{$\begin{array}{l}\text { Mean difference } \\
\text { IV, fixed, } 95 \% \mathrm{Cl}\end{array}$} & & \multirow{2}{*}{$\begin{array}{l}\text { Mean difference } \\
\text { IV, fixed, } 95 \% \mathrm{Cl}\end{array}$} & \\
\hline & Mean & SD & Total & Mean & SD & Total & & & & & \\
\hline Chan 2015 & 5.9 & 2.4 & 242 & 3.6 & 2.1 & 163 & $22.0 \%$ & $2.30[1.86,2.74]$ & & lat & \\
\hline Gui 2017 & 6.1 & 2.5 & 60 & 3.8 & 2.3 & 60 & $5.8 \%$ & $2.30[1.44,3.16]$ & & $=$ & \\
\hline Juhn 2008 & 6.6 & 3.2 & 174 & 4.1 & 1.9 & 348 & $16.1 \%$ & $2.50[1.98,3.02]$ & & $=$ & \\
\hline Jung 2010 & 6.3 & 4.1 & 170 & 2.8 & 1.3 & 348 & $10.8 \%$ & $3.50[2.87,4.13]$ & & $=$ & \\
\hline Marchand 2003 & 6.4 & 4.2 & 26 & 3.1 & 1.5 & 27 & $1.5 \%$ & $3.30[1.59,5.01]$ & & - & \\
\hline Nantanda 2013 & 7.2 & 3.4 & 203 & 3.4 & 2.4 & 163 & $12.1 \%$ & $3.80[3.20,4.40]$ & & $=$ & \\
\hline Nantanda 2014 & 7.1 & 3.1 & 200 & 4.3 & 2.6 & 160 & $12.4 \%$ & $2.80[2.21,3.39]$ & & $=$ & \\
\hline Romero-Espinoza 2018 & 6.8 & 2.6 & 42 & 3.5 & 1.8 & 78 & $5.5 \%$ & $3.30[2.42,4.18]$ & & . & \\
\hline Li 2017 & 6.6 & 2.5 & 106 & 3.2 & 1.4 & 90 & $13.8 \%$ & $3.40[2.84,3.96]$ & & $=$ & \\
\hline Total $(95 \% \mathrm{Cl})$ & & & 1223 & & & 1437 & $100.0 \%$ & $2.93[2.72,3.13]$ & & & \\
\hline \multicolumn{10}{|c|}{ Heterogeneity: $\chi^{2}=27.65, d f=8(p=0.0005) ; 1^{2}=71 \%$} & 1 & \\
\hline \multicolumn{8}{|c|}{ Test for overall effect: $Z=27.69(p<0.00001)$} & -100 & $\begin{array}{l}-50 \\
\text { CVA }\end{array}$ & $\begin{array}{l}50 \\
\text { SC }\end{array}$ & 100 \\
\hline
\end{tabular}

Figure 5. Forest plot for comparison of eosinophil count between cough variant asthma (CVA) and simple cough (SC)

\begin{tabular}{|c|c|c|c|c|c|c|c|c|c|c|}
\hline \multirow[t]{2}{*}{ Study or subgroup } & \multicolumn{2}{|c|}{ CVA } & \multicolumn{2}{|c|}{ SC } & \multirow[t]{2}{*}{ Weight } & \multirow{2}{*}{$\begin{array}{c}\text { Odds ratio } \mathrm{M}-\mathrm{H} \\
\text { fixed, } 95 \% \mathrm{Cl}\end{array}$} & \multirow{2}{*}{\multicolumn{3}{|c|}{$\begin{array}{c}\text { Odds ratio } \mathrm{M}-\mathrm{H} \\
\text { fixed, } 95 \% \mathrm{Cl}\end{array}$}} & \\
\hline & Mean & Total & Mean & Total & & & & & & \\
\hline Chan 2015 & 131 & 242 & 40 & 163 & $18.1 \%$ & $3.63[2.34,5.62]$ & & & $\rightarrow$ & \\
\hline Gui 2017 & 33 & 60 & 13 & 60 & $4.8 \%$ & $4.42[1.99,9.81]$ & & & - & \\
\hline Juhn 2008 & 94 & 174 & 67 & 348 & $17.0 \%$ & $4.93[3.30,7.35]$ & & & - & \\
\hline Jung 2010 & 90 & 170 & 69 & 348 & $17.6 \%$ & $4.55[3.05,6.79]$ & & & $\varpi$ & \\
\hline Marchand 2003 & 12 & 26 & 8 & 27 & $3.5 \%$ & $2.04[0.66,6.30]$ & & & - & \\
\hline Nantanda 2013 & 121 & 203 & 31 & 163 & $11.5 \%$ & $6.28[3.88,10.17]$ & & & $\simeq$ & \\
\hline Nantanda 2014 & 99 & 200 & 35 & 160 & $16.3 \%$ & $3.50[2.20,5.58]$ & & & 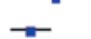 & \\
\hline Romero-Espinoza 2018 & 825 & 42 & 18 & 78 & $4.2 \%$ & $4.90[2.18,11.03]$ & & & 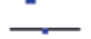 & \\
\hline Li 2017 & 58 & 106 & 17 & 90 & $6.9 \%$ & $5.19[2.70,9.96]$ & & & & \\
\hline Total $(95 \% \mathrm{Cl})$ & & 1223 & & 1437 & $100.0 \%$ & $4.44[3.73,5.29]$ & & & $\boldsymbol{\diamond}$ & \\
\hline Total events & 663 & 298 & & & & & & & & \\
\hline \multicolumn{7}{|c|}{ Heterogeneity: $\chi^{2}=6.20, \mathrm{~d} f=8(p=0.63) ; l^{2}=0 \%$} & & & & \\
\hline \multicolumn{7}{|c|}{ Test for overall effect: $Z=16.77(p<0.00001)$} & 0.01 & $\begin{array}{c}0.1 \\
\text { CVA }\end{array}$ & $\begin{array}{l}10 \\
\text { SC }\end{array}$ & 100 \\
\hline
\end{tabular}

Figure 6. Forest plot for number of positive IgM between cough variant asthma (CVA) and simple cough (SC)

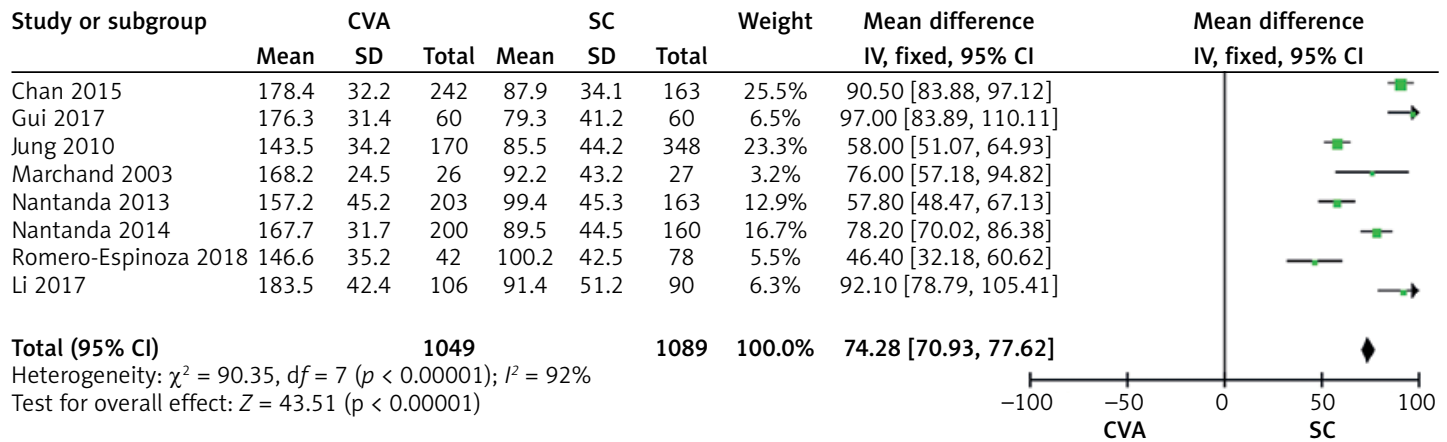

Figure 7. Forest plot for the sensitivity analysis of serum IgE level 


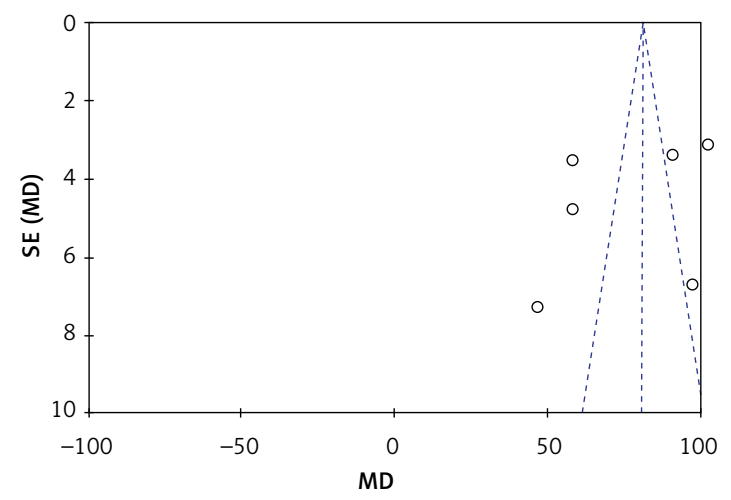

Figure 8. Begg's funnel plot of publication bias

$92 \%$, which suggested that the sensitivity of the article was stable.

\section{Bias analysis}

A funnel plot for serum IgE level in CVA and SC patients was performed. All the studies were included in the plot. The results showed some publication bias since the symmetrical characteristic of the funnel plot was not good (Figure 8).

\section{Discussion}

Asthma affects almost 30 million Americans and 300 million persons worldwide. The prevalence of asthma has increased over the past 2 decades in both children and adults [21-23]. CVA is a common cause of emergency hospital visits in low and medium income countries [24, 25]. Outcomes of children with CVA are influenced by age of the child, peripheral oxygen saturation on admission and adherence to asthma therapy.

Pneumonia and CVA are different disease entities with similar clinical presentations among young children. The diagnostic gold standards for pneumonia and CVA in young children are quite sensitive $[26,27]$. Pneumonia is considered the major cause of morbidity and mortality among children. Diagnosis is usually based on the presence of cough and/or difficulty in breathing, and rapid breathing with/without chest indrawing.

In the comparison of CVA and SC, IgE level in the CVA group was higher than that of the SC group. Since infection with Mycoplasma pneumoniae was highly related to IgE level, it could be interpreted that CVA was associated with mycoplasma pneumonia. Koh YY [28] reported that CVA can be secondary to mycoplasma pneumonia, which indicated that CVA and mycoplasma pneumonia had a strong relationship. When patients develop CVA, the possibility of mycoplasma pneumonia should be considered. Laboratory examinations should be carried out as soon as possible, and Mycoplasma pneumoniae should be removed in time.

The eosinophil count in the CVA group was more than that in the SC group, which is also an indicator of mycoplasma pneumonia. This supports the association between CVA and mycoplasma pneumonia.

The number of IgM positive patients was higher in the CVA group than that in the SC group. Mycoplasma pneumoniae would lead to a rise in the number of IgM positive patients. The number of IgM positive patients was not statistically significantly different between the CVA group and the SC group. Therefore, the association between CVA and mycoplasma pneumonia had further confirmation. Gui [29] reported that IgM can be used as a test for children with CVA. For screening CVA in children, eosinophil count and IgE level have high predictive value. Therefore, eosinophil count, IgE and $\operatorname{lgM}$ can be combined for early diagnosis of CVA. These articles further support the conclusion of this study.

This study had some limitations. First, more indicators such as gender and stratification of age in both the CVA and SC group should be analyzed since gender and age might influence the results, and will be evaluated in the future. Second, more indicators should be included to comprehensively analyze the results, which could be conducted in future studies. Third, articles from more countries could be included in future studies to guarantee the universality of the association. Fourth, all reported studies used serology to identify Mycoplasma pneumoniae infection, and none used culture or PCR; more identification methods could be included in the future.

In conclusion, based on the results of blood test including IgE, eosinophil count and positive IgM between the CVA group and the SC group, there may be a correlation between CVA and mycoplasma pneumonia, although the causation of mycoplasma pneumonia needs to be further studied. Therefore, comprehensive preventive measures such as avoiding smoke and air pollution should be adopted for CVA among children.

\section{Conflict of interest}

The authors declare no conflict of interest.

\section{References}

1. Chaves LE, Nascimento LFC, Rizol P. Fuzzy model to estimate the number of hospitalizations for asthma and pneumonia under the effects of air pollution. Rev Saude Publica 2017; 51: 55.

2. César AC, Nascimento LF, Mantovani KC, Pompeo Vieira LC. Fine particulate matter estimated by mathematical model and hospitalizations for pneumonia and asthma in children. Rev Paul Pediatr 2016; 34: 18-23. 
3. Gold DR, Litonjua AA, Carey VJ, et al. Lung VITAL: rationale, design, and baseline characteristics of an ancillary study evaluating the effects of vitamin $D$ and/or marine omega- 3 fatty acid supplements on acute exacerbations of chronic respiratory disease, asthma control, pneumonia and lung function in adults. Contemp Clin Trials 2016; 47: 185-95.

4. Zhou H, Zhou B, Xiang B. Relationship between lifestyle and family care among asthma child. J Modern Clin Med 2007; 12: 12-5.

5. Sun GF. The effect of family intervention on compliance of asthma child who inhale cortex steroids. Chin J Beha Med Sci 2004

6. Obata, Fumiya. Content of Asthma Child and Healthy Child's Internal Body Parts: Examination which Centers on Understanding of Function. Bull Spe Edu 2000:11522.

7. Hussein YM, Alzahrani SS, Alharthi AA, et al. Association of serum cytokines levels, interleukin $10-1082 \mathrm{G} / \mathrm{A}$ and interferon- $\gamma+874$ T/A polymorphisms with atopic asthma children from Saudi Arabia. Cell Immunol 2014; 289: 21-6.

8. Gulen F, Zeyrek D, Can D, et al. Development of new sensitizations in asthmatic children monosensitized to house dust mite by specific immunotherapy. Asian Pac J Allergy Immunol 2007; 25: 7-11.

9. Pajno GB, Morabito L, Barberio G, Parmiani S. Clinical and immunologic effects of long-term sublingual immunotherapy in asthmatic children sensitized to mites: a double-blind, placebo-controlled study. Allergy 2000; 55: 842-9.

10. Klug B, Bisgaard $\mathrm{H}$. Measurement of lung function in awake 2-4-year-old asthmatic children during methacholine challenge and acute asthma: a comparison of the impulse oscillation technique, the interrupter technique, and transcutaneous measurement of oxygen versus whole-body plethysmography. Pediatr Pulmonol 1996; 21: 290-300.

11. Friend JA. Do smoking parents seek the best advice for their asthmatic children? Thorax 2001; 56: 1.

12. Li W, Ban C, Zhang J, Hu Y, Han B, Han B. Correlation study of cough variant asthma and mycoplasma pneumonia infection in children. Pak J Pharm Sci 2017; 30 (3(Special)): 1099-102.

13. Marchand E, Etienne-Mastroianni B, Chanez P, Lauque D, Leclerc P, Cordier JF. Idiopathic chronic eosinophilic pneumonia and asthma: how do they influence each other? Eur Respir J 2003; 22: 8-13.

14. Juhn YJ, Kita H, Yawn BP, et al. Increased risk of serious pneumococcal disease in patients with asthma. J Allergy Clin Immunol 2008; 122: 719-23.

15. Jung JA, Kita H, Yawn BP, et al. Increased risk of serious pneumococcal disease in patients with atopic conditions other than asthma. J Allergy Clin Immunol 2010; 125: 217-21.

16. Chan JY, Stern DA, Guerra S, Wright AL, Morgan WJ, Martinez FD. Pneumonia in childhood and impaired lung function in adults: a longitudinal study. Pediatrics 2015; 135: 607-16.

17. Nantanda R, Tumwine JK, Ndeezi G, Ostergaard MS. Asthma and pneumonia among children less than five years with acute respiratory symptoms in Mulago Hospital, Uganda: evidence of under-diagnosis of asthma. PLoS One 2013; 8: e81562.

18. Romero-Espinoza JA, Moreno-Valencia Y, CoronelTellez RH, et al. Virome and bacteriome characterization of children with pneumonia and asthma in Mexico City during winter seasons 2014 and 2015. PLoS One 2018; 13: e0192878.

19. Nantanda R, Ostergaard MS, Ndeezi G, Tumwine JK. Clinical outcomes of children with acute asthma and pneumonia in Mulago hospital, Uganda: a prospective study. BMC Pediatr 2014; 14: 285.

20. Gui Y. Correlation between cough variant asthma in children and repeated mycoplasma pnenumonia infection. J Clin Pul Med 2017; 2: 276-79.

21. Van Bever HP, Desager KN, Lijssens N, Weyler JJ, Du Caju MV. Does treatment of asthmatic children with inhaled corticosteroids affect their adult height? Pediatr Pulmonol 1999; 27: 369-75.

22. Saha MT, Laippala P, Lenko HL. Growth of asthmatic children is slower during than before treatment with inhaled glucocorticoids. Acta Paediatr 1992; 86: 138-42.

23. Heaton T, Rowe J, Turner S, et al. An immunoepidemiological approach to asthma: identification of in-vitro T-cell response patterns associated with different wheezing phenotypes in children. Lancet 2005; 365: 142-9.

24. Munir AK, Björkstén B, Einarsson R, et al. Cat (Fel d I), $\operatorname{dog}($ Can $\mathrm{fl})$, and cockroach allergens in homes of asthmatic children from three climatic zones in Sweden. Allergy 1994; 49: 508-16.

25. Carswell F, Birmingham K, Oliver J, Crewes A, Weeks J. The respiratory effects of reduction of mite allergen in the bedrooms of asthmatic children - a double-blind controlled trial. Clin Exp Allergy 1996; 26: 386-96.

26. Leaderer BP, Belanger K, Triche E, et al. Dust mite, cockroach, cat, and dog allergen concentrations in homes of asthmatic children in the northeastern United States: impact of socioeconomic factors and population density. Environ Health Perspect 2002; 110: 419-25.

27. Bisgaard H, Gillies J, Groenewald M, Maden C. The effect of inhaled fluticasone propionate in the treatment of young asthmatic children: a dose comparison study. Am J Respir Crit Care Med 1999; 160: 126-31.

28. Koh YY, Chae SA, Min KU. Cough variant asthma is associated with a higher wheezing threshold than classic asthma. Clin Exp Allergy 1993; 23: 696-701.

29. Gui Q, Qian GS, Han J, Zhao ZQ. Genetic analysis of serum total IgE of pedigree member in asthma. Immu J 2004; 20. 